\title{
Pneumatic dilation for achalasia in a patient with esophageal varices
}

Authors

Institutions
Etienne Désilets ${ }^{1}$, Arthur Belle ${ }^{2}$, Christian Boustière ${ }^{2}$, Arthur Laquière ${ }^{2}$

Charles-Lemoyne Hospital, Gastroenterology Department, Longueuil, Canada

Saint Joseph Hospital, Hepato-gastro-enterology Department, Marseille, France submitted:

25. November 2015 accepted after revision: 8. February 2016

\section{Bibliography}

DOI http://dx.doi.org/

$10.1055 / \mathrm{s}-0042-103240$

Published online: 30.3.2016

Endoscopy International Open

2016; 04: E459-E460

(c) Georg Thieme Verlag KG

Stuttgart · New York

E-ISSN 2196-9736

\section{Corresponding author \\ Etienne Désilets, MD}

Charles-Lemoyne Hospital Gastroenterology Department Longueuil

Canada

Fax: +450-466-5036

etienne.desilets@usherbrooke. ca
Background and study aims: Previous reports of simultaneous presence of esophageal varices (EV) and achalasia suggest placement of a transjugular intrahepatic portosystemic shunt (TIPS) and surgical myotomy or endoscopic therapy. We re-

\section{Introduction \\ $\nabla$}

Simultaneous presence of esophageal varices (EV) and achalasia is an uncommon clinical scenario. Previous reports suggest placement of a transjugular intrahepatic portosystemic shunt (TIPS) and surgical myotomy or endoscopy therapy for treatment [1]. For patients who are not candidates for a TIPS, injection of the lower esophageal sphincter with botulinum toxin under endoscopic ultrasound (EUS) has been described [2 -3] but it offers only short-term relief.

\section{Case Report}

We report the case of a 64-year-old man who received anticoagulant therapy with warfarin for a myeloproliferative disorder with a history of portal thrombosis. The patient's main complaints were chronic esophageal dysphagia to solids and daily regurgitation of undigested food. He also reported weight loss of $30 \mathrm{~kg}$ in the last 6 months (total Eckardt score of 10, representing the sum of the symptom scores for dysphagia, regurgitation, chest pain and weight loss [4]). He did not have any history of EV band ligation. His physical exam was unremarkable aside from cachexia. Upper endoscopy showed a dilated esophagus above a contracted lower esophageal sphincter and grade $3 \mathrm{EV}$.

An EUS ( $\bullet$ Fig. 1) and thoracic scan both showed absence of external compression or neoplastic disease and the presence of esophageal collateral venous circulation. Manometry ( $\bullet$ Fig.2) confirmed the diagnosis of type 1 achalasia. Place- port the case of a 64-year-old man who received anticoagulant therapy for a myeloproliferative disorder with extensive portal thrombosis which was a contraindication to placement of a TIPS.

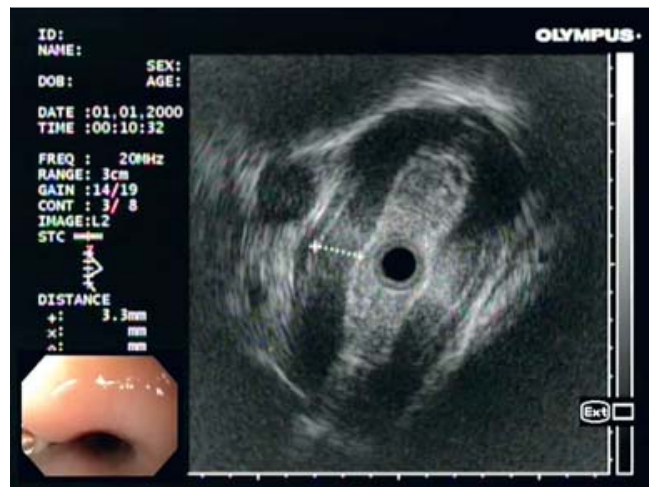

Fig. 1 EUS demonstrating absence of external compression or neoplastic disease and presence of esophageal collateral venous circulation.

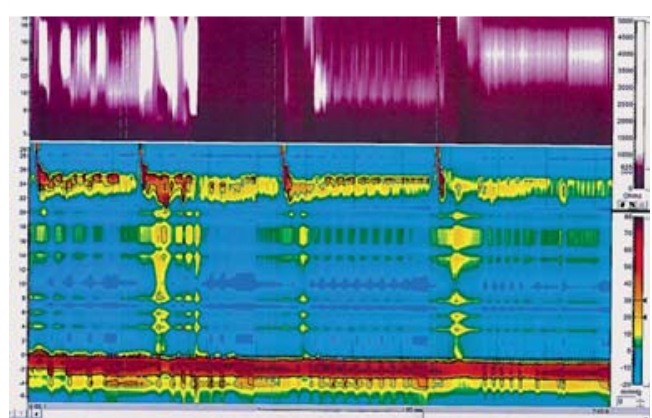

Fig.2 Manometry confirming the diagnosis of type 1 achalasia.

ment of a TIPS was contraindicated by presence of an extensive chronic portal thrombosis with cavernoma. The case was reviewed and discussed in a multidisciplinary meeting involving thoracic surgeons and advanced endoscopists experienced with Heller myotomy and POEM. Those two ther- 


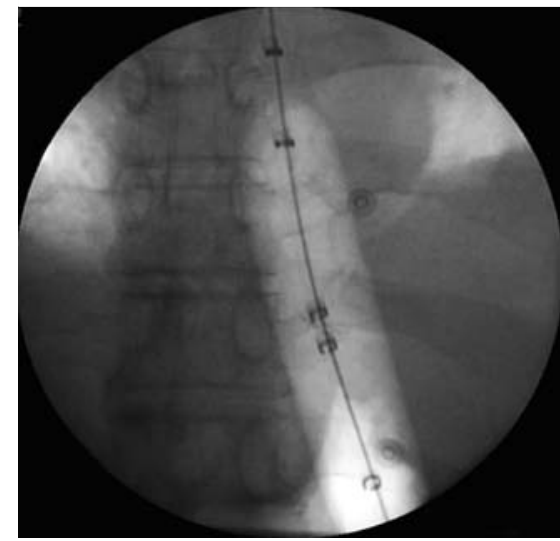

Fig. 3 Fluoroscopy showing balloon in place.

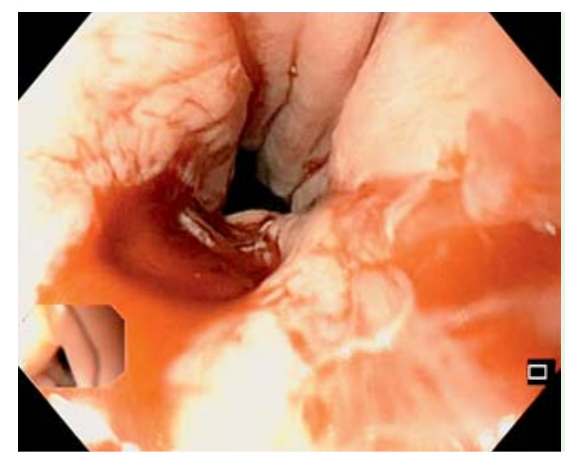

Fig. 4 Endoscopic view after pneumatic dilation.

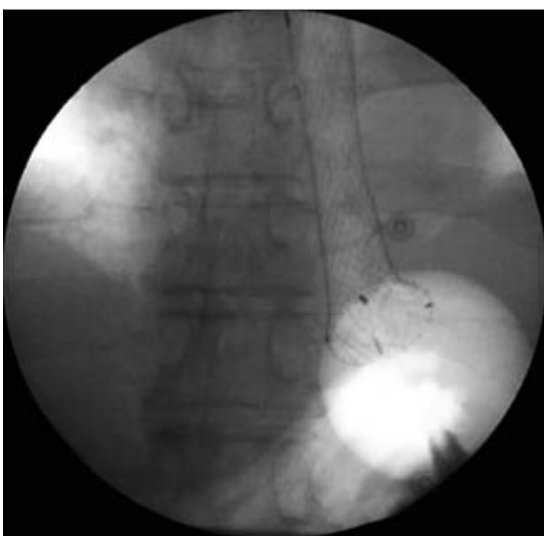

Fig. 5 Fluoroscopic view of stent implantation.

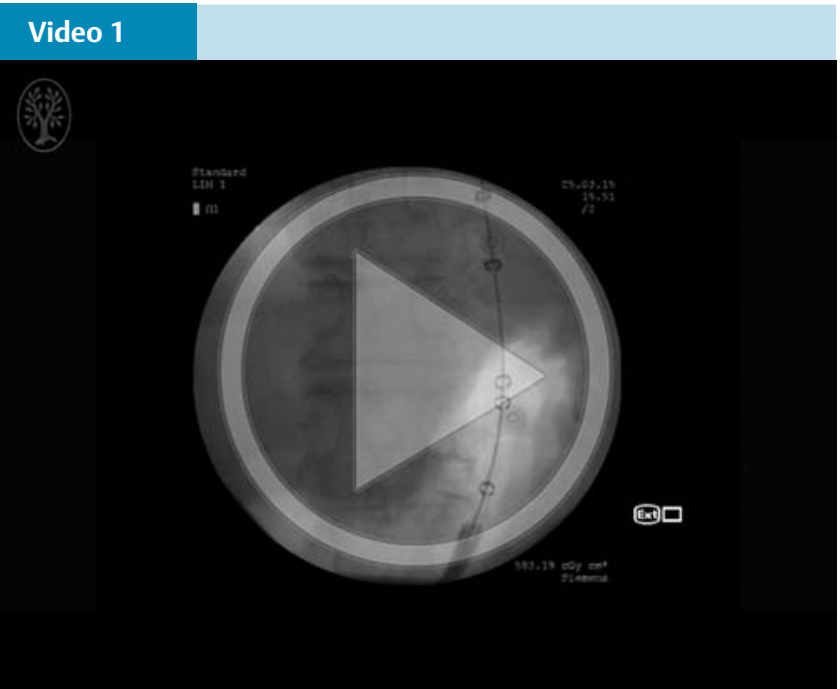

Case presentation. Online content including video sequences viewable at: http://dx.doi.org/10.1055/s-0042-103240 apeutic options were rejected because of the presence of numerous varices.

The patient was switched to low-molecular-weight heparin for anticoagulation and it was withheld before every endoscopic procedure. Over a period of 8 weeks, three endoscopic band ligation sessions were practiced to eradicate the EV. Once the varices were eradicated, with the patient under general anesthesia, we proceeded to pneumatically dilate his lower esophageal sphincter with a Rigiflex II ${ }^{\mathrm{TM}}$ 30-mm dilation balloon ( $\bullet$ Fig.3). The balloon was placed at the level of the lower esophageal sphincter and inflated to 20 psi for 30 seconds under fluoroscopic guidance. The endoscope was then reinserted to appreciate the dilation wound with visible muscle fibers ( $\bullet$ Fig.4). Soft venous bleeding was noted. Mainly for bleeding prophylaxis, we proceeded to implant a SX-ELLA Stent Danis ${ }^{\mathrm{TM}}(25 \times 135 \mathrm{~mm}$ covered metal stent) using the standard delivery technique with inflation of a gastric balloon wedged under the cardia ( $\bullet$ Fig.5). Again, fluoroscopic guidance was used. The patient resumed normal oral intake the day after both procedures and no complications were noted.

A week after the procedure, the patient was electively admitted for stent removal. A system consisting of a hook and an extractor was used, making the recapture less traumatic. The patient was discharged the same day. Clinical follow-up a month later confirmed the resolution of his dysphagia (total Eckhart score of 1). A brief case presentation and the endoscopic procedures are shown in a short video available online ( $\bullet$ Video $\mathbf{1})$.

\section{Conclusion}

To our knowledge, this is the first reported case of endoscopic balloon dilation for achalasia on a patient with EV without previous placement of a TIPS. This sequence of endoscopic techniques is safe and feasible in this rare and difficult therapeutic situation and it is a permanent solution for patients with EV for whom TIPS is unsuitable. Previous reports have described injection of botulinum toxin under EUS guidance but that option offers only temporary relief. The risk of hemorrhagic complications may be reduced with a covered esophageal stent implanted with a nontraumatic recapture system.

\section{Competing interests: None}

\section{References}

1 Pinillos H, Legnani P, Schiano T. Achalasia in a patient with gastroesophageal varices: problematic treatment decisions. Dig Dis Sci 2006; 51: $31-33$

2 Lozano-Lanagrán M, Lavín-Castejón I, Alcaín-Martínez G. Treatment of achalasia with botulinum toxin injection guided by endoscopic ultrasonography in a patient with esophageal varices. Rev Esp Enferm Dig 2011; 103: 663-664

3 Lakhtakia S, Monga A, Gupta R et al. Achalasia cardia with esophageal varix managed with endoscopic ultrasound-guided botulinum toxin injection. Indian J Gastroenterol 2011; 30: 277-279

4 Eckardt VF. Clinical presentations and complications of achalasia. Gastrointest Endosc Clin N Am 2001; 11: 281 - 292 